\title{
Epididymal Fat Pad Alterations in Mice with Spontaneous Obesity and Diabetes and with Chemically Induced Obesity
}

\author{
M.G. Soret, F.P. Kupiecki and B.M. Wyse \\ Pathology and Toxicology Research and Diabetes and Atherosclerosis Research, The Upjohn Company, Kalamazoo, \\ Michigan 49001, USA
}

Summary. Pathologic alterations have been found in the epididymal fat pad of five strains of spontaneously obese or diabetic mice and in one strain of normal mice made obese by a single injection of goldthioglucose. Histologic abnormalities were observed in the epididymal fat pad of all obese and diabetic mice. These abnormalities were at first characterized by a remarkable growth of the individual fat cell. Later, coinciding with a weight loss of the pad, and in some instances discoloration, the pad became hypercellular. A variable number of macrophages, mast cells and fibroblasts were observed occupying the intercellular spaces and a few fat cells appeared to be diminishing in size. - Overt necrosis and foci of acute inflammatory reaction of the epididymal fat pad was only seen in 9 month old T-KK mice. -- "Lean" KK mice, having at all times an underdeveloped epididymal fat pad, were free of the lesions mentioned above. - Prediction of the character and degree of the pathologic changes in the early stages could not be made by gross observation of the fat pad. Histologic methods appear to be necessary to ascertain the condition of the epididymal fat pad of mice having abnormal body weight or abnormal plasma insulin levels.

Key words: C57BL/6J mice, KK mice, T-KK mice, C57BL/6J-ob mice, C57BL/6J-Aya mice, C57BL/KsJ mice, C57BL/KsJ-db mice, epididymal fat pad cell, epididymal fat pad alterations, goldthioglucose induced obesity, spontaneous obesity in mice, hyperinsulinism in mice.

\section{Introduction}

A number of abnormalities, including hyperphagia, obesity, hyperglycemia, intermittent glucosuria and hyperinsulinemia, have been found in the T-KK mouse $[1,2]$, a strain produced by inbreeding offspring of $\mathrm{KK} \times \mathrm{C} 57 \mathrm{BL} / 6 \mathrm{~J}$ strains of mice [1]. The T-KK mice also have been found to have abnormal epididymal fat tissue. Appel and Dulin found that epididymal adipose tissue taken from these mice at the age of 6 months mobilized free fatty acids (FFA) at a reduced rate compared to controls (C57BL/6J) and incorporated less ${ }^{14} \mathrm{C}$ from glucose- $\mathrm{U}^{14} \mathrm{C}$ into total lipid, triglyceride glycerol and triglyceride FFA (personal communication). Also they noted that epididymal fat pads of T-KK mice were yellow-brown in color and in some cases atrophied or necrotic. Matsuo et al. have also reported discoloration of the epididymal fat pad in KK mice [3].

Recently it was shown that epididymal adipose tissue of T-KK animals was much less responsive to the lipolytic effect of epinephrine than tissue of control animals, in both the fed and fasted states [4]. The reduced response of epididymal fat to epinephrine was observed both in 10-12 week-old animals which had normal-colored tissue and in $32-36$ week-old mice which had yellow-brown fat pads that were not necrotic as judged from gross appearance.

It was considered of interest to study the histologic changes which may have accompanied these gross morphologic and metabolic alterations. In this report we present the results of a study of the pathologic changes of the epididymal fat pad from birth to the age of 12 months in T-KK, "lean" KK and "obese" KK mice as compared to $\mathrm{C} 57 \mathrm{BL} / 6 \mathrm{~J}$ controls. We also describe the pathologic changes found in the epididymal fat pad of a) spontaneously obese mice, b) chemically induced obese mice and c) 2 other strains of diabetic mice, at the ages of 3 and 9 months.

\section{Materials and Methods}

The present study includes a total of 272 male mice. $\mathrm{KK}$ and T-KK and some C57BL/6J mice were raised in the Upjohn colonies and C57BL/6J, C57BL/6J-ob, C57BL/6J-Aya, C57BL/KsJ and C57BL/KsJ-db were obtained from Jackson Laboratories, Bar Harbor, Maine. All mice were given Purina Mouse Chow and water ad libitum, unless otherwise indicated. The animals were classified by age and strain as follows:

\begin{tabular}{|c|c|c|c|c|c|c|c|c|c|}
\hline & $\begin{array}{l}\text { C57BL/ } \\
6 J\end{array}$ & "lean" & $\underset{\text { "obese" }}{\text { KK }}$ & $\mathrm{T} \cdot \mathrm{KK}$ & $\begin{array}{l}\mathrm{C} 57 \mathrm{BL} / \\
6 J-\mathrm{ob}\end{array}$ & 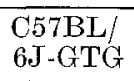 & $\begin{array}{l}\mathrm{C} 57 \mathrm{BL} / \\
6 \mathrm{~J}-\mathrm{A}^{\mathrm{y}}\end{array}$ & $\begin{array}{l}\mathrm{C} 57 \mathrm{BT} / \mathrm{f} \\
\mathrm{KsJ}\end{array}$ & $\begin{array}{l}\mathrm{C} 57 \mathrm{BL} / \\
\mathrm{KsJ}-\mathrm{db}\end{array}$ \\
\hline Newborn & 3 & 3 & - & 3 & 一 & - & - & - & - \\
\hline 14 days & 3 & 3 & - & 3 & - & $\ldots$ & - & - & - \\
\hline $14-20$ days & 27 & 31 & - & 35 & 一 & - & $\ldots$ & - & - \\
\hline 3 months & 14 & 16 & 6 & 15 & 6 & - & 6 & 6 & 6 \\
\hline 9 months & 11 & 13 & 6 & 15 & 6 & 9 & 5 & 3 & 1 \\
\hline 12 months & 3 & 4 & 7 & 3 & - & - & - & - & - \\
\hline
\end{tabular}


Body weight of all and fat pad weights of representative animals were taken at the time of autopsy. Blood glucose and plasma insulin were determined in most animals. For this purpose animals were fasted overnight and fed for two hours before they were bled. Blood glucose, measured by the Auto-Analyzer micro-prodedure [5] and plasma insulin, determined by the cellulose powder immunoassay [6] were measured in individual blood samples, except in 14-20 day old mice in which tests were made in 9 to 13 pools of blood representing 27 to 35 mice per strain. For the production of chemically-induced obesity a group of nine 3-month old C57BL/6J mice were injected once intraperitoneally with gold thioglucose [7] in corn oil at the rate of $0.5 \mathrm{mg} / \mathrm{g}$ body weight and killed at the age of 9 months [8]. Histologic examinations of the epididymal fat pads were made on Bouin's fixed-
3 months of age than during the remaining part of the 12 month period. The average weight of a 3 to 12 month old C57 male mouse was about $31 \mathrm{~g}$.

KK Mice. KK mice were slightly underweight during the first 2 weeks of life but grew at a fast rate in the following 10 weeks. At the end of that time they were clearly divided into "lean" and "obese" types.

"Lean" $K K$ 's were heavier than controls at 3 and 9 months of age, but lost weight after 9 months and were lighter than the corresponding controls at the end to the year.

Most "Obese" $K K$ 's from 3-12 months of age weighed $51 \mathrm{~g}$ or more; the average body weight for the whole group being $54 \mathrm{~g}$. By the end of the 12 month period only a few mice showed some weight decline.

Table 1. Body and single epididymal fat pad weights in 7 strains of mice at different ages. Average values are given. The numbers in parentheses indicate the numbers of observations

\begin{tabular}{|c|c|c|c|c|c|c|c|c|c|}
\hline \multirow[b]{3}{*}{$\mathrm{C} 57 \mathrm{BL} / 6 \mathrm{~J}$} & \multicolumn{5}{|c|}{ Body weights $(\mathrm{g})$} & \multicolumn{4}{|c|}{ Single epididymal fat pad $\left(\mathrm{mg}^{*}\right)$} \\
\hline & $\begin{array}{l}\text { New- } \\
\text { born }\end{array}$ & $\begin{array}{l}14 \\
\text { days }\end{array}$ & $\begin{array}{l}3 \\
\text { months }\end{array}$ & $\begin{array}{l}9 \\
\text { months }\end{array}$ & $\begin{array}{l}12 \\
\text { months }\end{array}$ & $\begin{array}{l}14 \\
\text { days }\end{array}$ & $\begin{array}{l}3 \\
\text { months }\end{array}$ & $\begin{array}{l}9 \\
\text { months }\end{array}$ & $\begin{array}{l}12 \\
\text { months }\end{array}$ \\
\hline & $2 \quad(3)$ & $\begin{array}{l}7.7(3) \\
8.5(27)\end{array}$ & $\begin{array}{l}25(11) \\
28(3)\end{array}$ & $\begin{array}{l}30(8) \\
32(3)\end{array}$ & $33(3)$ & $20(3)$ & $290(3)$ & $380(3)$ & $585(3)$ \\
\hline KK-lean. & 1.9 & $\begin{array}{l}6.0(3) \\
7.8(31)\end{array}$ & $\begin{array}{l}34(6) \\
34(10)\end{array}$ & $\begin{array}{l}36(3) \\
33(10)\end{array}$ & $26(4)$ & $2(3)$ & $190(3)$ & $229(3)$ & $22(3)$ \\
\hline KK-obese & - & - & $\begin{array}{l}54(3) \\
56(3)\end{array}$ & $\begin{array}{l}51(2) \\
53(4)\end{array}$ & $\begin{array}{l}58(3) \\
41(4)\end{array}$ & - & $1060(3)$ & $597(3)$ & $408(3)$ \\
\hline T-KK & $1.7(3)$ & $\begin{array}{l}7.4(3) \\
8.1(35)\end{array}$ & $\begin{array}{l}35(3) \\
33(12)\end{array}$ & $\begin{array}{l}43(3) \\
43(12)\end{array}$ & $39(3)$ & $18(3)$ & $716(3)$ & $150(3)$ & $60(3)$ \\
\hline C57BL/6J-ob & - & - & $54(6)$ & $70(6)$ & - & - & $1953(6)$ & $643(6)$ & - \\
\hline $\begin{array}{l}\text { C57BL/6J-GTG } \\
\text { obese }\end{array}$ & - & - & - & $48(6)$ & - & - & $\rightarrow$ & $1729(6)$ & - \\
\hline $\begin{array}{c}\text { C57BL/6J-GTG } \\
\text { non-obese }\end{array}$ & - & - & - & $30(3)$ & - & - & - & $512(3)$ & - \\
\hline C57BL/KsJ & - & - & $26(6)$ & $26(3)$ & - & $\cdots$ & $257(6)$ & $190(3)$ & - \\
\hline $\mathrm{C} 57 \mathrm{BL} / \mathrm{K} \mathrm{sJ}-\mathrm{db}$ & - & $\ldots$ & $54(6)$ & $49(1)$ & - & - & $1211(6)$ & $455(1)$ & - \\
\hline C57BL/6J-A ${ }^{-}$ & - & - & $44(6)$ & $49(5)$ & - & - & $1128(6)$ & $783(5)$ & 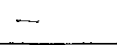 \\
\hline
\end{tabular}

paraffin embedded-five micron sections stained by the following methods: hematoxylin-eosin (Harris), allochrome (Lillie), aldehyde-fuchsin-light green (ScottHalmi) with or without oxidation, toluidine blue 0 (Manocchio), toluidine blue 0 (Mowry) with and without sulfation, ferro-cyanide-safranin (Perls), sudan black B (Chifelle and Putt) and carbol fuchsin-iron hematoxylin (Verhoeff-Masson).

\section{Results}

\section{Body Weight}

A summary of average weights is presented in Table 1.

C57BL/6J. The normal control, C57BL/6J mice, experienced a steady gain in body weight up to the age of 12 months. This growth was much faster before
$T K K$ Mice. TKK Mice were slightly underweight at birth and at 14 days of age but were heavier than the corresponding $\mathrm{C} 57 \mathrm{BL} / 6 \mathrm{~J}$ controls at 3 months of age. These animals experienced some weight increase in the next 6 months and some decline by the age of 12 months.

$C 57 B L / K s J-d b$ Mice. C57BL/KsJ-db mice were significantly heavier than $\mathrm{C} 57 \mathrm{BL} / \mathrm{KsJ}$ controls at 3 months of age. The single 9 month old survivor, although heavier than the controls, showed some body weight loss.

$C 57 B L / 6 J-G T G$ Mice. Six of the 9 GTG-treated C57BL/6J mice became significantly obese during the six month post-treatment period.

$C 57$ BL/6J -ob Mice. Significantly high body weights were observed in C57BL/6J-ob mice, both at 3 and 9 months of age, the weight of 9 month old mice being significantly higher than that of 3 month old mice. 
C57BL/6JA $A^{y}$ a Mice. Body weights of C57BL/ $6 \mathrm{~J}-\mathrm{A}^{\mathrm{y}} \mathrm{a}$ mice were significantly higher than those of normal controls at 3 and 9 months of age, but the individual weights were not excessively high.

\section{Weight and Gross Appearance of the Epididymal Fat $P a d$}

The epididymal fat pad, practically negligible in all newborn mice, was clearly differentiated by the 14th day of age in the strains examined.

However, marked variations were observed in the size of the pad from strain to strain ,at that early age and up to the age of 12 months. A summary of these findings is presented in Table 1.

$C 5^{4} B L / 6 J$. In C57BL/6J the growth of the epididymal fat pad was steady, from $20 \mathrm{mg} / \mathrm{pad}$ in 14 dayold mice to 290,380 and $585 \mathrm{mg}$ in 3,9 and 12 month old mice respectively. Gross appearance of the fat
The gross appearance and color of the pad in KK's at the age of 9 months was similar to that of normal controls, but in 12 months old "obese" KK's it was yellowish while in the year old "lean" KK's it was clearly atrophic and brownish or fleshy colored.

$T K K$ Mice. In 14 day old T-KK's the epididymal fat pads were similar in size to those of their corresponding controls. By the age of 3 months the epididymal fat pads of all T-KK mice were more than twice normal size. Nine month old T-KK's were heavier than normal but their epidiymal pad had experienced a marked size reduction to about half of that in 9 month old controls. The reduction in size was most noticeable at the cephalic end of the pads, which appeared yellowish in 9 mice and brownish in 3 . This involution of the fat pad continued through the age of 12 months. At this age the epididymal fat was, on the average, about $1 / 10$ th the normal size.

Table 2. Blood sugar and plasma insulin levels in 7 strains of mice at different ages

\begin{tabular}{|c|c|c|c|c|c|c|c|c|}
\hline & \multicolumn{4}{|c|}{$\begin{array}{l}\text { Blood sugar levels ( } \mathrm{mg} / 100 \mathrm{ml}) \\
\text { Averages - number of animals () }\end{array}$} & \multicolumn{4}{|c|}{$\begin{array}{l}\text { Plasma insulin levels }(\mu \mathrm{U} / \mathrm{ml}) \\
\text { Averages }- \text { number of animals }()\end{array}$} \\
\hline & $\begin{array}{l}14-20 \\
\text { days }\end{array}$ & $\begin{array}{l}3 \\
\text { months }\end{array}$ & $\begin{array}{l}9 \\
\text { months }\end{array}$ & $\begin{array}{l}12 \\
\text { months }\end{array}$ & $\begin{array}{l}14-20 \\
\text { days }\end{array}$ & $\begin{array}{l}3 \\
\text { months }\end{array}$ & $\begin{array}{l}9 \\
\text { months }\end{array}$ & $\begin{array}{l}12 \\
\text { months }\end{array}$ \\
\hline $\mathrm{C} 57 \mathrm{BL} / 6 \mathrm{~J}$ & $124(27)$ & $136(11)$ & $138(11)$ & $136(3)$ & $4.5(27)$ & $23(11)$ & $49(11)$ & $78(3)$ \\
\hline KK-lean & $107(31)$ & $\begin{array}{l}155(10) \\
137(6)\end{array}$ & $118(10)$ & $93(4)$ & $10 \quad(31)$ & $\begin{array}{r}92(10) \\
238(6)\end{array}$ & $91(10)$ & $46(4)$ \\
\hline KK-obese & - & $290(6)$ & $153(4)$ & $136(7)$ & - & $1021(6)$ & $1435(4)$ & $443(7)$ \\
\hline T-KK & $117(35)$ & $156(12)$ & $95(12)$ & $106(3)$ & $(35)$ & $315(12)$ & $1797(12)$ & $278(3)$ \\
\hline C57BL/6J-ob & & & $\mathrm{ND}^{\mathrm{a}}$ & & & & ND & \\
\hline $\begin{array}{l}\text { C57BL/6J-GTG } \\
\text { obese }\end{array}$ & & & $146(6)$ & & & & $199(6)$ & \\
\hline $\begin{array}{l}\text { C57BL/6J-GTG } \\
\text { non-obese }\end{array}$ & & & $132(3)$ & & & & $72(3)$ & \\
\hline $\mathrm{C} 57 \mathrm{BL} / \mathrm{K}_{\mathrm{s}} \mathrm{J}$ & & $193(5)$ & $123(3)$ & & & $30(5)$ & $10(3)$ & \\
\hline C57BL/KsJ-db & & $\begin{array}{l}503(5) \\
507(6)\end{array}$ & $110(1)$ & & & $\begin{array}{l}759(5) \\
214(6)\end{array}$ & $140(1)$ & \\
\hline $\mathrm{C} 57 \mathrm{BL} / 6 \mathrm{~J}-\mathrm{A}^{\mathrm{y}} \mathrm{a}$ & & & ND & & & & ND & \\
\hline
\end{tabular}

a $\mathrm{ND}=$ Not Done

pad in this strain of mice was considered normal at all times.

KK Mice. KK mice appeared underdeveloped by the 14th day of age, both in body weight and size of the epididymal fat pad. At 3 months of age "lean" KK mice, although heavier than their C57 counterparts, had a much smaller epididymal fat pad. "Obese" 3 month old KK's were much heavier and had an epididymal pad much larger than that of their controls. The epidıdymal fat pad of "lean" 9 month old KK's showed some increase in size, although never reaching that of their controls. In the 9 month old "obese" KK's the fat pad was still large, in spite of a marked reduction in size from the peak observed 6 months earlier. By the age of 12 months a fast involution of the epididymal fat pad had occurred in "lean" KK mice, and a continuous but slower fat pad weight loss was observed in "obese" KK's.
$C 5 \% B L / 6 J-G T G$. At the age of 9 months, six of the 9 GTG treated $\mathrm{C} 57 \mathrm{BL} / 6 \mathrm{~J}$ mice were obese $(43-$ $60 \mathrm{~g})$ and their epididymal fat pad correspondingly enlarged (average $1729 \mathrm{mg}$ ). The body weight of the remaining 3 was normal but their epididymal fat pads were slightly enlarged. The gross appearance of all 9 fat pads was unremarkable.

$C 5^{4} B L / K s J$ and $C 5^{4} B L / K s J-d b$. The size of the epididymal fat pad of 3 month old $\mathrm{C} 57 \mathrm{BL} / \mathrm{KsJ}$ 's was comparable to that of $\mathrm{C} 57 \mathrm{BL} / 6 \mathrm{~J}$ mice, but a significant loss of weight was observed in 9 month old KsJ mice. The fat pad of $\mathrm{C57BL} / \mathrm{KsJ}_{\mathrm{s}} \mathrm{db}$ mice was significantly larger than either control (C57BL/6J and C57BL/KsJ) at the age of 3 and 9 months, although a significant decline was observed in the only 9 month old survivor.

$C 57 B L / 6 J_{-o b}$ and $C 5 \% B L / 6 J^{y}{ }^{y} a$. A similar trend was observed in the remaining two strains of mice examined. At 3 and 9 months of age C57BL/6J-ob 


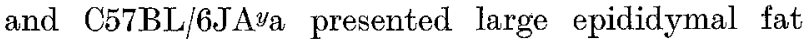
pads although the pads were significantly smaller at the age of 9 months.

\section{Blood Glucose and Plasma Insulin}

A summary of average blood sugar and plasma insulin levels is presented in Table 2.

C57BL/6J. The levels of blood sugar in C57BL/6J mice did not change significantly with age. However,
Blood sugar of the "lean" KK mice returned to normal values by 9 months of age and below normal values at 12 months of age. "Obese" KK's had slightly elevated blood sugar at 9 months and normal values at 12 months. Plasma insulins of "lean" and "obese" KK mice were significantly elevated at 3 months of age, with those of the "obese" mice also being higher than the "lean" KK mice. Plasma insulin levels of "lean" KK mice were slightly elevated at 9 months

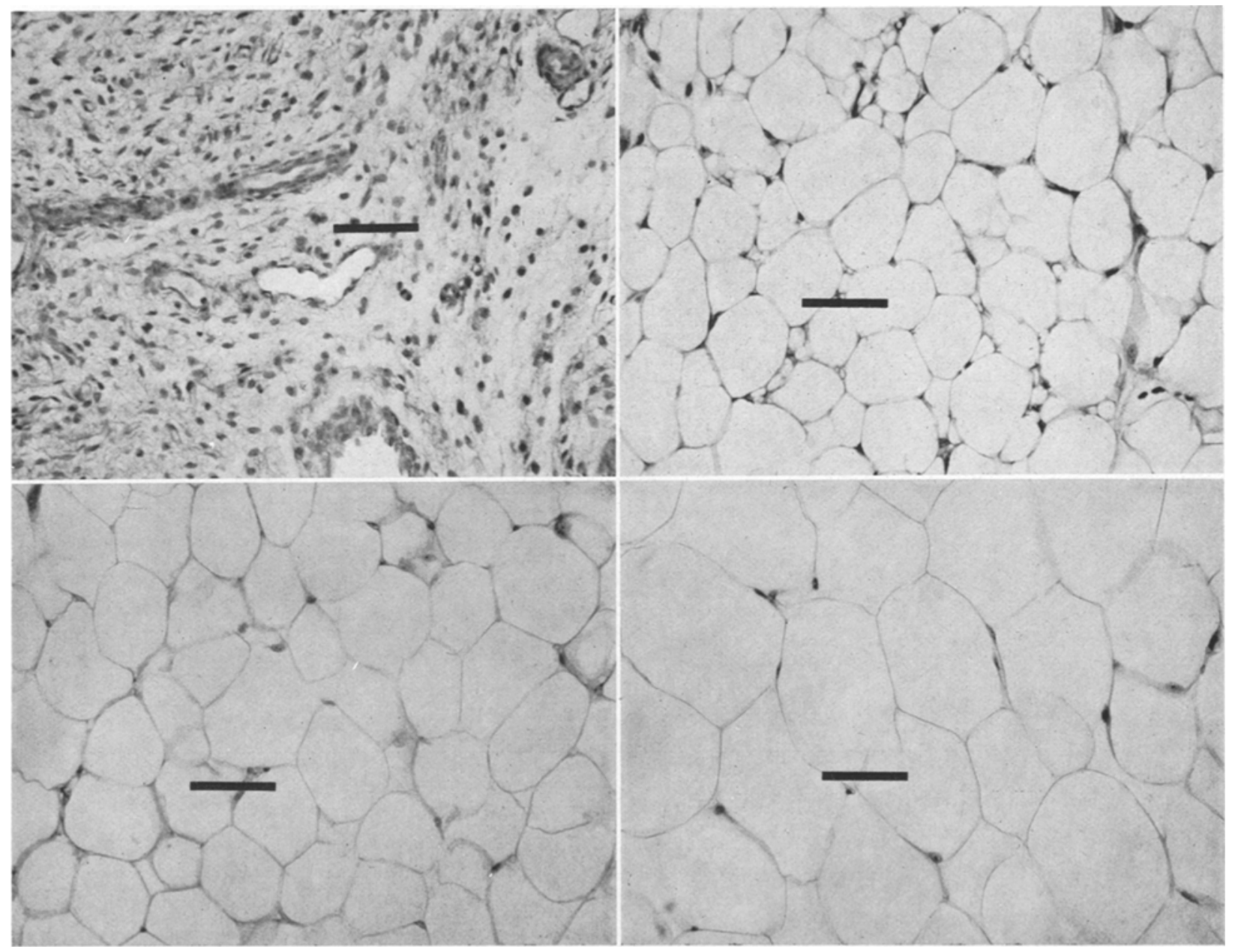

Figs. 1-4. Material fixed in Bouin's, stained with allochrome. Bars = $50 \mu$. Fig. 1. Primitive epididymal fat pad. C57BL/6J mouse, 1 day old. Fig. 2. Normal epididymal fat cell. C57BL/6J mouse, 14 day old. Fig. 3. Normal epididymal fat pad cell. C57BL/6J mouse, 3 month old. Fig. 4. Normal epididymal fat pad cell. C57BL/6J, 9 month old. The individual fat cell has grown with age

plasma insulin levels rose slightly up to the age of 12 months, although this rise may not have been significant after 9 months of age.

$K K$ Mice. Blood sugar was significantly low in 14-20 day old KK mice and significantly high in 3 month old "obese" and some 3 month old "lean" KK mice. The blood glucose of "obese" KK's was also significantly higher than that of "lean" KK's. and normal at 12 months, while in "obese" KK's they were still markedly elevated at 9 and 12 months of age, although the values at 12 months were much lower than at 9.

$T-K K$ Mice. In T-KK's a slight depression of blood glucose at 14-20 days of age was not significant, but the differences observed thereafter, elevation at 3 months and depressions at 9 and 12 months, were 
statistically significant. Insulin levels were significantly high at all times, rising to the highest values at 9 months of age and declining thereafter.

$C 57 B L / K s J-d b$ Mice. C57BL/KsJ-db's blood sugar and plasma insulin were significantly high at $2-3$ months of age but at 9 months the only surviving mouse showed a blood sugar level drop to normal and some decline of the still high plasma insulin level.

\section{Histologic Observations}

The periepididymal tissue of one day old mice was found to be made up of primitive adipose cells, regardless of the strain of mice (Fig. 1). Differentiation and growth of the epididymal fat pad cell occurred by the 14th day of age but at a different rate in the 3 strains of mice studied at this age (Figs. 2, 6, 9).

$C 57 B L / 6 J$ Mice. In C57BL/6J mice a negligible

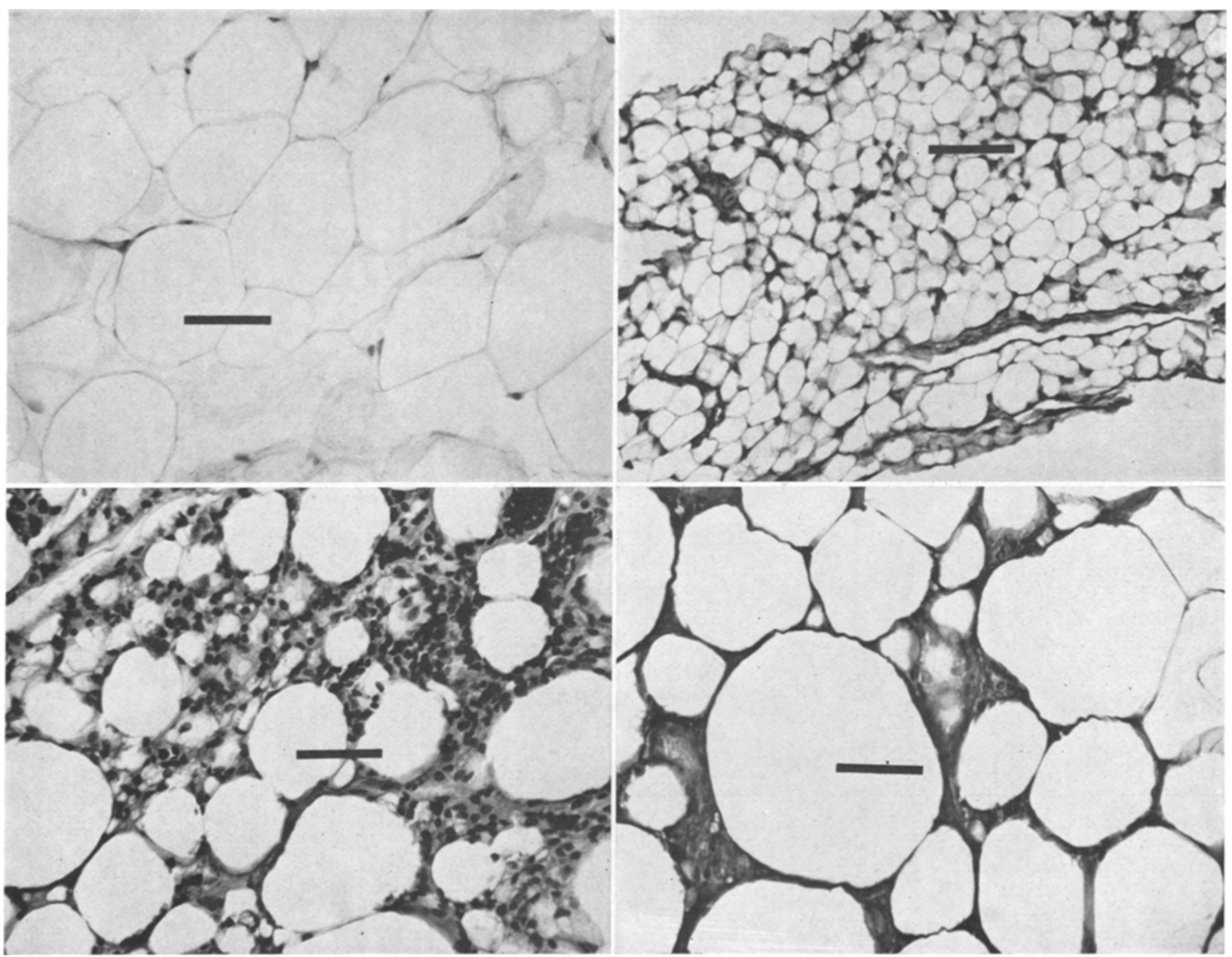

Figs. 5-8. Material fixed in Bouin's, stained with allochrome. Bars $=50 \mu$. Fig. 5. Normal epididymal fat cell. C57BL/ $6 J, 12$ month old. The adipoeyte size has remained stable. Fig. 6 . Underdeveloped epididymal fat cell typical of 14 day old KK mouse. Fig. 7. "Lean" KK mouse, 12 month old. Reduced number and size of fat-containing cells of the epididymal fat pad. Fig. 8. "Obese" KK mouse, 12 month old. Hypercellularity at the cephalic end of the epididymal fat pad

C57BL/6J-GTG Mice. Blood glucose values of 9 month old obese C57BL/6J-GTG mice were elevated about the same as those of "obese" KK mice. Plasma insulin values were higher than control values, but were much lower than the values observed in 9 month old "obese" KK's and T-KK's. Values obtained from 9 month old lean C57BL/6J-GTG mice were normal.

No blood sugar or plasma insulin were determined in ob or Aya mice. growth of the fat cell occurred from 2 weeks (Fig, 2) to 3 months of age (Fig. 3), and after a moderate growth which took place from 3 to 9 months (Fig. 4), the adipocyte size remained stable through the age of 12 months (Fig. 5).

$K K$ Mice. The epididymal fat pad cell of 14 day old KK's was underdeveloped (Fig. 6), a feature which agrees with the lower than normal body and epididymal fat pad weights. A noticeable growth of 
the adipocyte occurred in the following 10 weeks, at which time KK mice were classified as either "lean" or "obese". The adipocytes of "lean" KK's were similar or slightly smaller than those in $\mathrm{C} 57 \mathrm{BL} / 6 \mathrm{~J}$ controls, while in "obese" KK's the fat cells were larger than normal.

Growth of the fat cell in "Iean" KK mice up to the age of 9 months closely followed that of corre- common to the 3 fat pads were the presence of mast cells in the interstitial spaces and the absence of inflammation or necrosis.

The evolution of the epididymal fat pad in "obese" KK's followed the pattern observed in the corresponding T-KK's (see below) at the ages of 3 and 9 months (Figs. 10 and 11, respectively). However, no signs of leukocytic infiltration, necrosis or hyper-

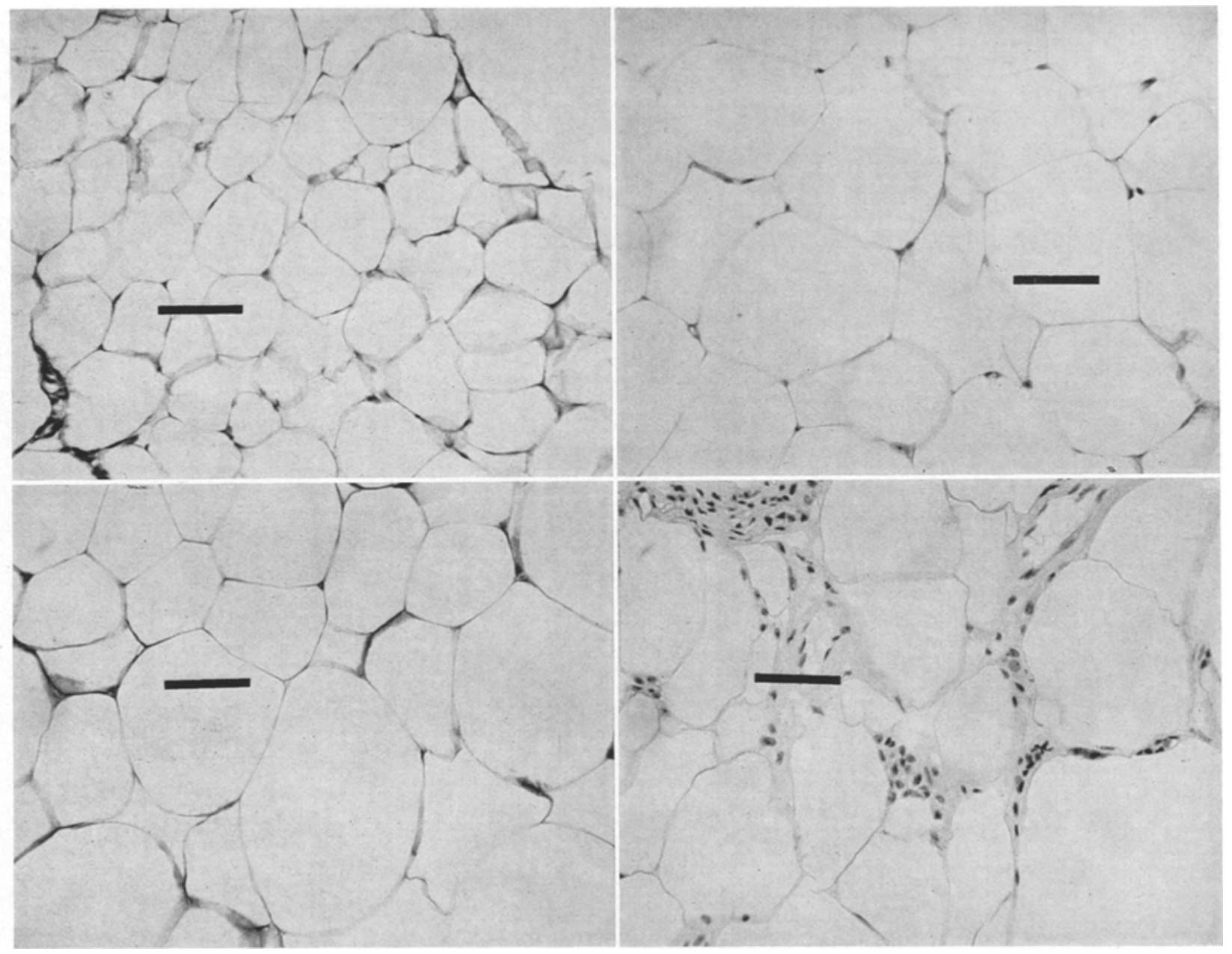

Fig's. 9-12. Material fixed in Bouin's, stained as follows: Figs. 9 to 11, allochrome; Fig. 12, hematoxylin and eosin. Bars $=50 \mu$. Fig. 9. Overdeveloped epididymal fat cell typical of 14 day old Toronto-KK mouse. Fig. 10 . Large epididymal fat cell. Toronto-KK mouse, 3 month old. Fig. 11. The epididymal fat pad cell of 9 month old T-KK mouse has grown to a very large size. Fig. 12. T-KK, 9 mo. old. Increased number of fibroblasts in thickened intercellular spaces. Very large fat cells

sponding controls. By the age of 12 months, however, a remarkable involution of the epididymal fat pad was observed in all "lean" KK mice which corresponded to a reduction of the number and size of fat-containing cells (Fig. 7). The histologic appearance of the fat pad in the 3 "lean" one year old KK mice examined varied, depending on the number of fatless adipocytes and on the size of the fat cells present. However, cellularity were observed in 9 months old "obese" KK's, as was the case in comparable T-KK's.

The 12 month old "obese" KK mouse was still obese and had. a large, though reduced, epididymal fat pad. Of the three 12 month old "obese" KK's examined, one had large fat cells while the other two presented some size reduction of the fat cell and increased cellularity at the cephalic end of the epi- 
didymal fat pad (Fig. 8). The elements occupying the intercellular space were macrophages, mast cells and occasionally a few round cells. Polymorphonuclear leukocytes were either absent or scarce.

$T-K K$ Mice. The periepididymal adipocytes of T-KK's were at all times larger than those of comparable controls from the ages of 14 days to 9 months (Figs. 9, 10, 11). However, at 9 months of age other histologic changes were observed in the epididymal number of fibroblasts and an occasional macrophage. In other 9 month old animals the intercellular space was larger and contained a variety of cells. As shown in Fig. 13, the intercellular space was rich in fibroblasts and collagen and a few microcysts found in these areas were lined by polymorphonuclear leukocytes which probably represented the initial inflammatory reaction to recently necrotized fat cells. A few macrophages and mast cells were found both in the microcysts and
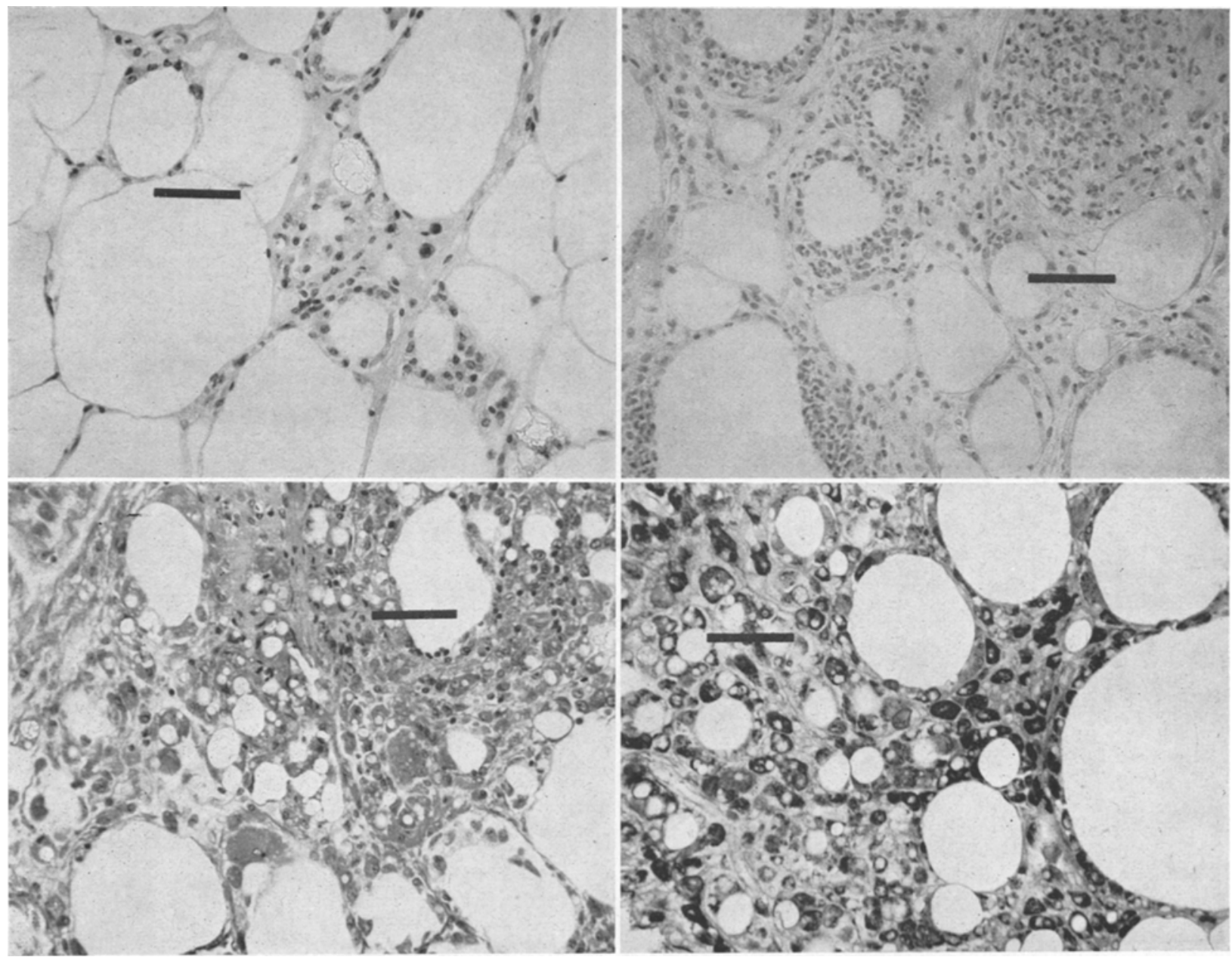

Figs. 13-16. Material fixed in Bouin's stained as follows: Figs. 13 and 14, hematoxylin and eosin; Fig. 15, allochrome; Fig. 16, aldehyde fuchsin-light-green. Bars $=50 \mu$. Fig. 13. T-KK, 9 mo. old. Further thickening of intercellular space, increased cellularity, cyst formation. Fig. 11. T-KK, 9 mo. old. Acute inflammation of epididymal fat. Leukocytic infiltration, fibrosis. Fig. 15. T-KK, 9 mo. old. Foreign body type granuloma. Giant cells, macrophages, mast cells, leukocytes, collagen matrix. Fig. 16. T-KK, 9 mo. old. Mast cells and macrophages (black in the picture).

fat pad of T-KK mice, namely a marked increase in cellularity (comprising fibroblasts, leukocytes, macrophages and mast cells), a variable degree of micro-cyst formation, capillary hemorrhages, fat necrosis and atrophy.

The degree of abnormalities observed in 9 month old T-KK's varied considerably from animal to animal. In some of these animals (Fig. 12) the intercellular space appeared containing an increased in the intercellular space. At this time many of the fat cells were still very large. Some of the fat pads were found to be replaced by either a granulomatous tissue infiltrated by polymorphonuclear leukocytes and a few round cells as shown in Fig. 14 or by a foreign body type of granuloma in which giant cells, macrophages and mast cells were predominant, as shown in Fig. 15. A nearby area (Fig. 16) shows the abundance of deeply stained mast cells and macrophages. Al- 
though the number of mast cells was in fact increased, as demonstrated by the use of metachromatic stains (Fig. 17), most of the background was occupied by macrophages. Siderophages were quite abundant in many sections (Fig. 18) while lipophages were found in most preparations (Fig. 19).

The epididymal fat pad of 12 month old T-KK's of some "obese" KK's. Mast cells and macrophages were found in these areas of hypercellularity, in contrast with the scarcity of these cells in other areas of the fat pad. The largest epididymal fat pad cells in this group of "obese" GTG-treated mice were found in the mouse having the heaviest body and epididymal fat pad weights.

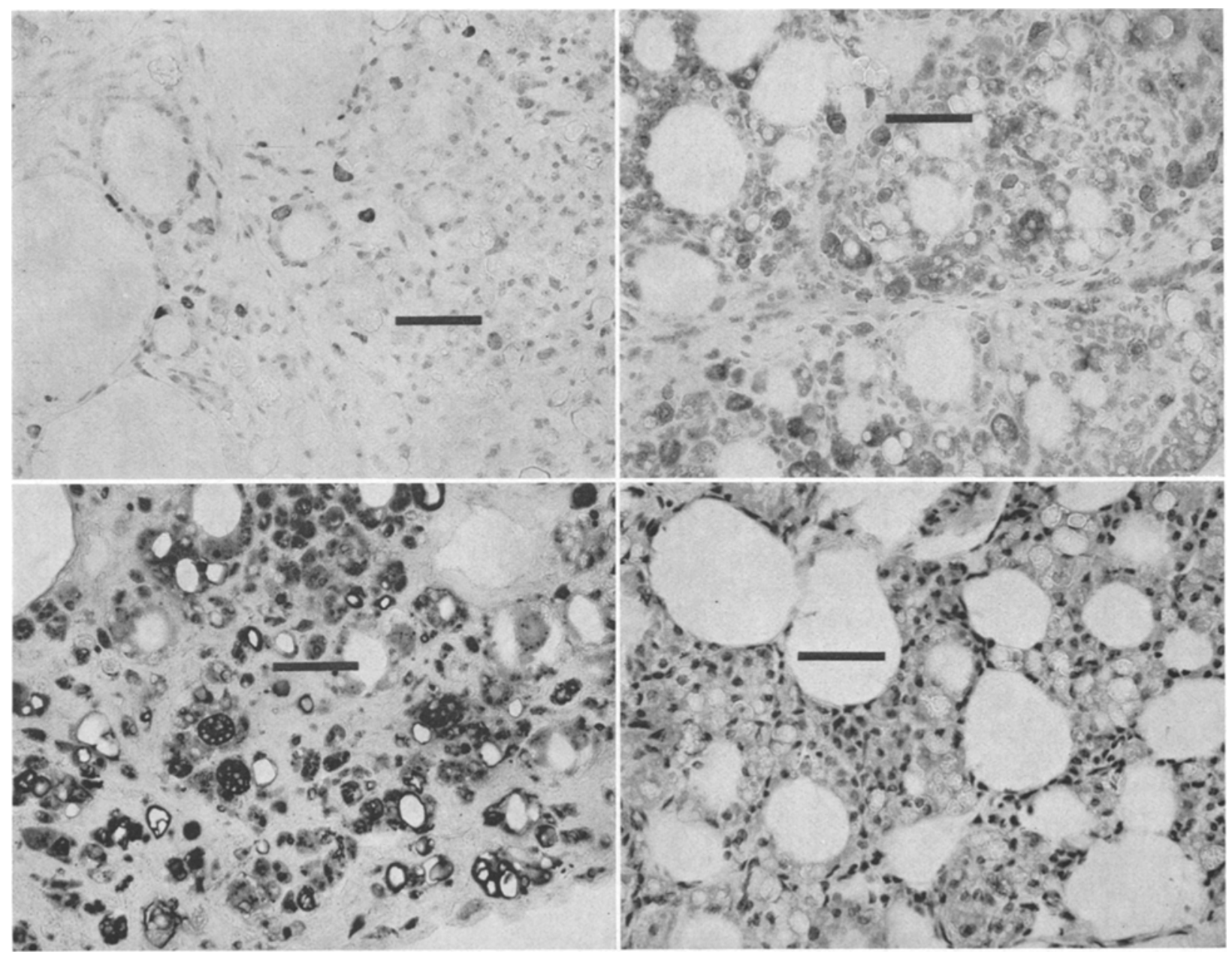

Figs. 17-20. Material fixed in Bouin's, stained as follows: Fig. 17, Toluidine blue 0; Fig. 18, ferrocyanide-safranin; Fig. 19, Sudan black B; Fig. 20, hematoxylin and eosin. Bars $=50 \mu$. Fig. 17. T-KK, 9 mo. old. Mast cells stained metachromatically (black in the picture). Fig. 18. T-KK, 9 mo. old. Abundant mast cells (black) associated with numerous siderophages (gray). Fig. 19. T-KK, 9 mo. old. Lipophages stained in black. Fig. 20. T-KK, 12 mo. old. Brownish epididymal fat pad. A few fat cells remain in caudal area of the pad

was, for the most part, totally atrophied, except for a few fat cells still present in the caudal area of the pad (Fig. 20).

$C 57 B L / 6 J-G T G$. The microscopic appearance of the epididymal fat pad tissue of 9 month old lean GTG-treated C57BL/6J mice was similar to that of 9-12 month old untreated controls. In 3 the of 6 obese GTG-treated mice the periepididymal adipocytes were larger and the intercellular space was slightly hypercellular in a few areas, resembling the fat pad
$C 5 \% B L / K s J, \quad C 57 B L / K s J-d b, C 5 \% B L / 6 J \cdot o b$ and $C 5^{7} B L / 6 J A^{y} a$ Mice. The remaining four strains of mice were examined at the ages of 3 and 9 months. The histologic appearance of the epididymal fat pad of 3 and 9 month old C57BL/KsJ mice was unremarkable, resembling that of C57BL/6J's. A "normal" increase in the size of the fat cell was observed in this period, in spite of the weight loss recorded for the fat pad by the end of the 6 month interval. The periepididymal fat pad of $\mathrm{C} 57 \mathrm{BL} / 6 \mathrm{~J}_{-} \mathrm{ob}, \mathrm{C} 57 \mathrm{BL} /$ 
$\mathrm{KsJ}-\mathrm{db}$ and $\mathrm{C} 57 \mathrm{BL} / 6 \mathrm{~J}-\mathrm{A}^{\mathrm{y}} \mathrm{a}$ resembled the fat pad of "obese" KK mice in that: a) the adipocyte was abnormally large both at 3 and 9 months of age, b) a moderate degree of hypercellularity was observed at 9 months of age occurring simultaneously with a weight loss of the epididymal fat pad, and c) no necrosis or inflammatory reaction was observed in the fat tissue.

\section{Discussion}

It has been postulated that the number of fat cells in the gonadal fat pad appears to be determined early in life and the normal number of fat cells of the epididymal fat pad remains constant throughout life. The enlargement of the fat depot, therefore, results from increased lipid deposition in the already existing fat cells [9]. The abnormal increase in size of fat pads in some of the strains of mice examined in the present study was associated with an excessive increase in the size of the individual fat cell. The growth of the epididymal fat pad in the normal control, C57BL/6J mice, was the result of a moderate enlargement of the fat cell that was associated with age up to the age of 12 months. As the animals grew older, however, a number of new non-fat cells appeared in the epididymal fat pad and, in this sense, all these normal old fat pads were slightly "hypercellular". A variety of pathologic changes, involving the size of the fat cell and hypercellularity, was observed in the periepididymal fat depot of obese and diabetic mice and has been described in this report. Some of the changes were quite obvious, but most of the alterations were subtle enough to escape unrecognized on gross examination of the fat pad. Since this tissue is widely used for metabolic studies, it was considered of interest to determine the character and degree of these changes in different strains of mice and to find whether some parameters, such as body weight, epididymal fat pad weight or plasma insulin levels, would be indicative of the degree of fat pad alterations.

The development of the normal control C57BL/6J mice from birth to one year of age included a parallel and steady gain in total body and epididymal fat pad weights. In contrast, in the spontaneously obese and diabetic mice between the ages of 3 and 9 months, the epididymal fat underwent a variable but marked weight loss, whether the body weight increased (T-KK's, Ava's, and ob's), remained stable ("lean" KK's and "obese" KK's), or decreased (db's). In chemically induced obesity (GTG's) both body and epididymal fat pad weight gains were observed, the latter occurring at a very high rate during the 6 month period.

Contrary to Hausberger's statement [9], degree and duration of obesity were not the best indicators of fat pad alteration. This was evident from the fact that the ob's and the "obese" KK's, the heaviest mice for a relatively long period of time in this series, presented minor changes as compared with the remarkable alterations observed in T-KK's which at all times were much lighter animals. All animals presenting alterations of the gonadal fat pad had, at one time or another, abnormal levels of plasma insulin. While the worst alterations at 9 months of age were found in the group of animals with the highest insulin values (T-KK's) other obese mice ("obese" KK's) with longer duration of high levels of plasma insulin were not as severely affected at the age of 9 months.

More indicative of fat pad alteration was a sharp drop in the weight of the epididymal fat pad itself (in T-KK's, from $716 \mathrm{mg} / \mathrm{pad}$ at 3 months of age to $150 \mathrm{mg} / \mathrm{pad}$ at 9 months), but the actual severity of the pathologic changes could not be predicted on this basis alone. Discoloration of the fat pad was the best indication of serious alterations in the gonadal fat pad and those pads presenting a brownish color showed the highest degree of alterations. On the other hand, some pads presenting a relatively high degree of hypercellularity showed an unremarkable gross aspect.

In a group by itself was the "lean" KK mouse. Slightly hyperinsulinemic from 3 to 9 months of age, these animals were heavier than controls of the same age but presented underdeveloped epididymal fat pads. Three months later these mice were underweight and their fat pads were reduced to a small remnant of brownish tissue. It should be noted that the one year old "lean" KK's were the only mice in this series that at any time presented plasma insulin values below that of their corresponding control. Furthermore plasma growth hormone levels were found to be elevated in the same 1 year old "lean" KK"s [10]. The combined occurrence of a very sharp drop of plasma insulin levels with an elevation of plasma growth hormone levels could be considered synergistic factors leading to the reduction of the fat content of the gonadal fat pad.

The character of the histologic changes observed varied also from strain to strain. In all cases, except for "lean" KK's, the most remarkable change was the excessive enlargement of the fat cell.

The hypercellularity observed was light in GTG's and Aya's and moderate in ob's, db's and "obese" KK's, as compared to that observed in T-KK's, and it was characterized by the presence of macrophages, a few round cells, fibroblasts and an increased frequency of mast cells. Fat necrosis and inflammatory reaction observed in the epididymal fat depot of all 9 and 12 month old T-KK's were absent in the other strains studied.

Although Hellman et al. called the attention to the considerable accumulation of mast cells in the fat pad of the obob mouse and cautioned on the importance of expressing lipogenic activity as a function of the number of fat cells used and not per tissue weight, nitrogen or DNA, no mention was made 
of other histologic changes in the epididymal fat tissue [11].

Hellman again [12] stated that "the lower number of fat cells per unit of adipose tissue in the adult $\mathrm{A}-\mathrm{O}$ mice was not associated with any decrease of the relative nitrogen content as compared with $\mathrm{AN}$-mice". He did not explain the lack of correlation, although 2 years earlier [11] he had stressed the importance of including histologie methods for studying this tissue, as non-fat cells "may contribute very much to the total number of cells in the fat depots". Undoubtedly he was referring to the considerable accumulation of mast cells in the fat tissues of obese mice.

In "lean" KK's the character of the alterations of the epididymal fat pad was totally different. From 14 days to 9 months of age, and while plasma insulin levels were elevated, the fat pad cell was never larger and the fat pad was always smaller than those of the normal controls. By the age of 12 months most of the pad cells were either small or almost fatless. At no time was there fat cell enlargement and the type of hypercellularity found in all other hyperinsulinemic mice was never observed. In normal 9 month old KsJ's the epididymal fat pad had normal fat cell size and cellularity in spite of reduced fat pad weight and very low plasma insulin levels.

\section{Conclusions}

1. The weight of the epididymal fat pad of normal mice increases with age and its growth is parallel to gains in body weight up to the age of 12 months.

2. The epididymal fat pad of spontaneously obese and diabetic mice undergoes a sharp weight loss between the ages of 3 and 9 months which is independent from body weight gain or loss.

3. The weight loss of the epididymal fat pad in "lean" KK mice occurs after 9 months of age. However, the fat pad in this animal was underdeveloped at all times.

4. The opposite trend was observed in chemically induced obesity. The epididymal fat pad in these animals underwent a sharp weight gain between 3 and 9 months of age.

5. Histologic abnormalities were observed in the epididymal fat pad of all obese and diabetic mice. These abnormalities were at first characterized by a remarkable growth of the individual fat cell. Later, coinciding with a weight loss of the pad, and in some instances discoloration, the pad became hypercellular. A variable number of macrophages, mast cells and fibroblasts were observed occupying the intercellular spaces and a few fat cells appeared to be diminishing in size.

6. Overt necrosis and foci of acute inflammatory reaction of the epididymal fat pad was only seen in 9 month old T-KK mice.

7. "Lean" KK mice, having at all times an underdeveloped epididymal fat pad, were free of the lesions mentioned above. Defective fat deposition may have accounted for the small size of the fat pad and for the small size of the fat deposited in the individual fat cell.

8. Histologic methods are necessary to obtain dependable information regarding the "cellular" condition of the epididymal fat pad of mice having abnormal weight or abnormal plasma insulin levels.

\section{References}

1. Dulin, W.E., Wyse, B.M. : Diabetes in the KK mouse. Diabetologia 6, 317-323 (1970)

2. Appel, M.C., Chang, A.Y., Dulin, W.E.: Metabolic abnormalities in livers and islets of Langerhans in a diabetic mouse. Physiologist 14, 103 (1971)

3. Matsuo, T., Shino, A., Iwatsuka, H., Suzuoki, Z.: Endocr. jap. 17, 477 (1970)

4. Kupiecki, F.P., Adams, L.D.: The lipolytic system in adipose tissue of the T-KK and C57BL/KsJdb mice. Adenylyl cyclase phosphodiesterase and protein kinase activities. Diabetologia 10, 633-637 (1974)

5. Gerritsen, G.C., Dulin, W.E. : Effect of a new hypoglycemic agent 3,5 dimethyl pyrazole on carbohydrate and free fatty acids metabolism. Diabetes 14, 507 (1965)

6. Zaharto, D.D., Beck, L.V.: Studies of a simplified plasma insulin immunoassay using cellulose powder. Diabetes 17, 444 (1968)

7. Marshall, N.B., Barnett, R.J., Mayer, J.: Hypothalamic lesions in goldthioglucose injected mice. Proc. Soc. exp. Biol. (N.Y.) 90, 240 (1955)

8. Johnson, P.R., Hirsh, J.: Cellularity of adipose depots in 6 strains of genetically obese mice. J. Lipid Res. 13, $2(1972)$

9. Hausberger, F.X.: Pathological changes in adipose tissue of obese mice. Anat. Record 154, 651 (1966)

10. Wyse, B.M.: unpublished

11. Hellman, B., Larson, S., Westman, S.: Mast cell content and fatty acid metabolism in the epididymal fat pad of obese mice. Acta physiol. scand. 58, 255 (1963)

12. Hellman, B.; Studies in obese-hyperglycemic mice, Ann. N.Y. Acad. Sci. 131, 541 (1965)

Dr. M. G. Soret

Pathology and Toxicology Research

and Diabetes and Atherosclerosis

Research

The Upjohn Company

Kalamazoo, Mich. 49001

USA 